\title{
A study on the effectiveness of learning soft skills to HUFI students
}

Pham Chau Tuong Vy ${ }^{1 *}$

1 Ho Chi Minh City University of Food Industry; pctvpctv31033013@gmail.com

* Correspondence: pctvpctv31033013@gmail.com ; Tel.: +84 981126271

\begin{abstract}
Today, education and qualifications are not enough to determine the recruitment of workers for many businesses and employers. Soft skills are a major differentiating factor for employability and professional success today. This is true for almost all fields, regardless of the sector. The businesses are also demanding in terms of skills for employees. Therefore, it is extremely necessary to cultivate soft skills for students in the university. To ensure students are fully equipped with soft skills, HUFI has also implemented the teaching of essential and appropriate soft skills for students. The research paper revolves around the concept, role, and development of soft skills today, and highlights the effectiveness of soft-skills learning for HUFI students. Besides, it also shows the interest and recognition of students' soft skills.
\end{abstract}

Keywords: Soft skills, hard skills, HUFI students, job, effective, importance, knowledge, learning, employees.

\section{Introduction}

This section discusses the results and conclusions of previously published studies, to help explain why the current study is of scientific interest.

According to the second issue of the World Economic Forum, 75 million jobs will be lost by 2025 (Forum, 2018). However, the digital transition is expected to result in the production of 133 million jobs. Obviously, we'll find various positions related to emerging technology and digital apps among the most sought-after jobs. Employees with more creativity are also required in the marketing department. Employees with more creativity, aligned with the more recent trend are also required in the marketing department. However, the future remains unclear. But one thing is certain: the more you focus on your soft skills in addition to your hard skills, the easier it will be to enter the job market in the future.

Awareness underpins the development of a digital economy, which can take many forms, including dynamic problem solving, creativity and imagination, simulation of emerging markets, considering social and global implications, operating in new environments, and designing new products and services, among others...

A simple fact is that businesses need a team of high-quality employees, but many graduates have failed to meet the recruitment requirements, especially in terms of skills. Some students do well in school but graduate unable to find jobs, while others do not well in school but work very effectively and efficiently. One of the most important factors is a skill, which is often ignored by students.

Soft skills are important not only for future jobs but also for daily life and the learning process. What a difference it would make if we were taught soft skills from the beginning of our education. Recognize the importance of teaching students soft skills. As a result, HUFI has long promoted the teaching and learning of soft skills, and it is now soft skills become a requirement for graduation, ensuring that students, whether study- 
ing or graduating, have the required soft skills. Furthermore, HUFI students recognize the importance and efficacy that it provides, so the soft skills subject is a favorite among students.

\section{Literature review}

\section{Definition of soft skill.}

The term "soft skills" was coined by the United States Military in 1972. They excelled in the use of machines during their training, but they found that the majority of the success factor for soldiers was the way the group is led. As a result, they began to devise a method for capturing this mode of information acquisition. According to Wikipedia, the CONARC conference on soft skills was held in 1972 as well. At the conference, Dr. Paul Whitmore defined soft skills as: "important job-related skills that involve little or no interaction with machines and whose application on the job is quite generalized"

(Dr.Whitmore, 1972).

Nowadays soft skills are more and more popular and Marry K.Pratt defined that soft skills as a personal attribute that supports situational awareness and enhances an individual's ability to get a job done (Pratt, 2019). The term soft skills are often used as a synonym for people skills or emotional intelligence. Unlike hard skills, which describe a person's technical ability to perform a specifically defined task, soft skills are broadly applicable across job titles and industries.

Soft skills have looked a term referring to a set of transferable skills that are very important for success in the workplace. They comprise common sense, interpersonal skills, emotional intelligence, character traits as well as communication skills among others (Duszynski, Soft Skills, 2021).

Another way we can simply understand.

- $\quad$ Skill: The ability to effectively apply knowledge about the mode of action that has been acquired by the subject to perform the corresponding tasks.

- $\quad$ Soft: The non-technical nature

"Soft-skills" is also called: personal skill, EQ...

\section{The importance of soft skills.}

Soft skills predict success in life (Heckman, 2012). Soft skills contribute to determining who you are, how you work and how effective you are. Wherever you are, whatever you do, soft skills are essential. This type of skill is needed by everyone, from men to women, old to young. For students, it is even more important to cultivate and practice soft skills. Otherwise, as soon as you graduate, you will be easily left behind. Employers today are paying more and more attention to soft skills, sometimes also referred to as 2st century skills (Council, 2021). Even many people have fallen into long-term unemployment. When you are equipped with early and adequate soft skills, you will easily adapt and integrate better. In addition, you also have a method of studying, working scientifically, with high efficiency. If hard skills are considered a necessary condition, soft skills are a sufficient condition. Hard skills get you through one door while soft skills open many more. Soft skills help promote professional knowledge and skills to reach success. 
Hard skills are abilities that let you tackle job-specific duties and responsibilities. Hard skills can be learned through courses, vocational training, and on the job (Tomaszewski, 2021).

Some people claim that hard and soft skills are linked. Soft skills, according to some people, cannot be easily distinguished from discipline-specific hard skills and are just as important as hard skills. It's pretty simple to teach discipline-specific hard skills to people who already have the necessary soft skills. Individuals who lack soft skills, on the other hand, would find it more difficult to improve them. Hard skills are rigid, fixed, and change little. Soft skills are flexible, can be customized according to the situation and environment. They go hand in hand and complement each other. For example, if you want to become a doctor, you must have full medical skills and medical knowledge, besides a doctor also needs to be able to communicate well with patients to facilitate communication. more in treatment. But for salespeople, it is different, for them, attracting customers is extremely important, so communication skills are very important besides the basic knowledge elements. Therefore, hard skills and soft skills are often put on the scale and compared to see which side is "heavier". From the perspective of an employer, they will expect you to have both skills. So the common answer is that every skill is important. However, that importance is not always in equilibrium. Depending on your position in society, the balance between hard skills and soft skills will change.

It is often said that a college degree is your ticket to an interview, but soft skills will help you get and keep that job. Soft skills play an important role in the effective use of hard skills to achieve employment goals (S, 2020). So we can conclude that soft skills are the "lever" that promotes the existence and "sublimation" of hard skills.

\section{Soft skills in education.}

If teachers want to have a strong impact on their students and make their classes lively and memorable, in addition to the knowledge of the lesson that has been prepared, they also need good communication skills. It is difficult for students to pay attention to the lesson and their attention needs to be captured by the use of creative techniques in the lesson. Teachers also act as mentors and guides for their students and only when they have soft skills can they guide students on the right path and give them useful advice. Teachers should not be so distant that students feel unapproachable when solving a problem of any kind.

For students, in their learning process, they not only have to acquire knowledge but also need to have soft skills so that learning can be easy and they can express their own abilities. Students must be encouraged from a very young age to form opinions and defend what they believe. Therefore, presentation skills or giving opinions are also complementary skills for students in the learning process. To ensure student skill development, in-school education and at-home parents must work together to ensure that a student's school experience will also foster the social and personal skills to ensure their success when the future is part of the workforce. The same goes for students, themselves should see the role of soft skills in addition to hard knowledge to be able to cultivate themselves in the most comprehensive way.

Seth Godin published has an article. The thrust of his article was that 'soft skills' were the key to success in leadership and perhaps even happiness in life (Godin, 2017). We shouldn't be calling them 'soft' when they are hard to acquire skills. Hard skills can be assessed through the results of the academic process from books and academics, but soft skills are quite vague, difficult to assess and measure. They are only clearly shown through communication, handling, learning, and working. 
The importance of soft skills seems to be easy for everyone to see, so can the education industry. Gradually, soft skills classes were introduced into teaching, or simply extracurricular sessions to strengthen students' skills, students also gradually appeared in the learning process. Soft skills are also naturally reinforced by students in a way that is not forced. From basic extracurricular sessions, outdoor activities in middle and high school years also help students to be more confident or strengthen their ability to work in groups when participating in extracurricular games. At universities, soft skills have also been introduced into the curriculum, for example, HUFI has also made soft skills certificates a part of graduation requirements. In order to meet the demand for soft skills training, there are currently soft skills training centers in Vietnam.

\section{Extensive soft skills in HUFI include}

- Self-motivation and goal-building skills: "Self-motivation skills" are pivotal in channelizing our lives in the right direction by empowering our inner core with positivity and emotional intelligence to believe in our abilities in the toughest of circumstances (Bhasin, 2020). "Goal-building skills" is the ability to skill to set goals for yourself and achieve them

- Effective teamwork skills consist of interrelated abilities that let you work effectively in an organized group (Duszynski, 2021).

- Goal-setting and planning skills help you understand the importance of goals and the techniques involved in setting achievable goals paves the way for success (Elaine Houston, 2020)

- Vocational guidance and preparation for future job skills assist us in finding the right career for us, grasping current job trends. A vocation is a career or calling and the word is derived from the Latin vocare, which means "to call." Vocational guidance means helping someone find his or her calling or at least a suitable career choice (Isaac, 2012) And equip the necessary skills when preparing to apply for a job.

- $\quad$ Problem-solving and decision-making skills help you determine the source of a problem and find an effective solution (Team, 2020) Along with it is decision-making skills, having this skill will help us become steadfast, wise people to make the most necessary decisions.

- Creative thinking skills are the skills to consider something in a new way (Doyle, 2020). Creative thinkers can see things in new, unorthodox ways and come up with solutions that have never been thought of before.

- Leadership/team-building skills are knowing how to help individuals work as a cohesive group where all members feel invested in the direction and accomplishments of the team (Doyle, Important Team Building Skills That Employers Value, 2020).

- Job search skills and conquer employers help us see and find a job that is right for us and have the necessary skills to successfully get into that job, it will be very difficult for us without this skilled support when faced the strict censorship of the interview round.

\section{Materials and Methods}

To serve the study on the effectiveness of soft-skills learning to HUFI students a survey was therefore created. The survey mainly wants to find out the interest and preferences of HUFI students in soft skills, as well as the effects that soft skills bring to them. 
The survey design was completed through a process of careful thought and research to ask the most relevant and effective questions. There are 10 questions in the survey, languages include both English and Vietnamese. In addition to the information collection questions, there are also questions to collect opinions such as students' interest and desire for further development of soft skills at HUFI.

\section{Participants}

The survey participants included 101 HUFI students. In order to collect diverse data, the number of students participating in the survey did not discriminate between students of which year and faculty. Participants are randomly selected and have the most equitable outcomes largely based on their personal opinions.

\section{Assessment and measures}

After completing the collection of surveys, the results are aggregated in the form of a chart to easily see the difference of choices. From the obtained results, preliminary conclusions will be drawn and some comments will be added to clarify the research.

\section{Results}

HUFI is a school that emphasizes soft skills when it gives necessary and appropriate skills into electives for students of different disciplines. For example, a foreign language student like me will be trained in skills such as communication skills, information technology application skills, or a seemingly abstract but highly effective skill. like the effective study skills, we experienced in our freshman year. Besides, HUFI also opens extensive skill classes for all students with eight common soft skills. Students who are self-selected and completing four skills will then be awarded a certificate. It is not only seen as a necessary condition to meet graduation requirements, moreover, it is also an affirmation to businesses where HUFI students will work in the future that HUFI students have been trained and trained to create the most perfect way.

Of those eight soft skills, HUFI students will be supported to learn four skills for free, and that is just enough of the required number of skills to receive a skill certificate. Therefore, I believe that HUFI students will choose for themselves the skills that they feel are the most necessary and necessary for them. That can be clearly seen in the following chart. This is the result of the question: "What soft skills did you learn?"

\section{What soft skills did you learn?}

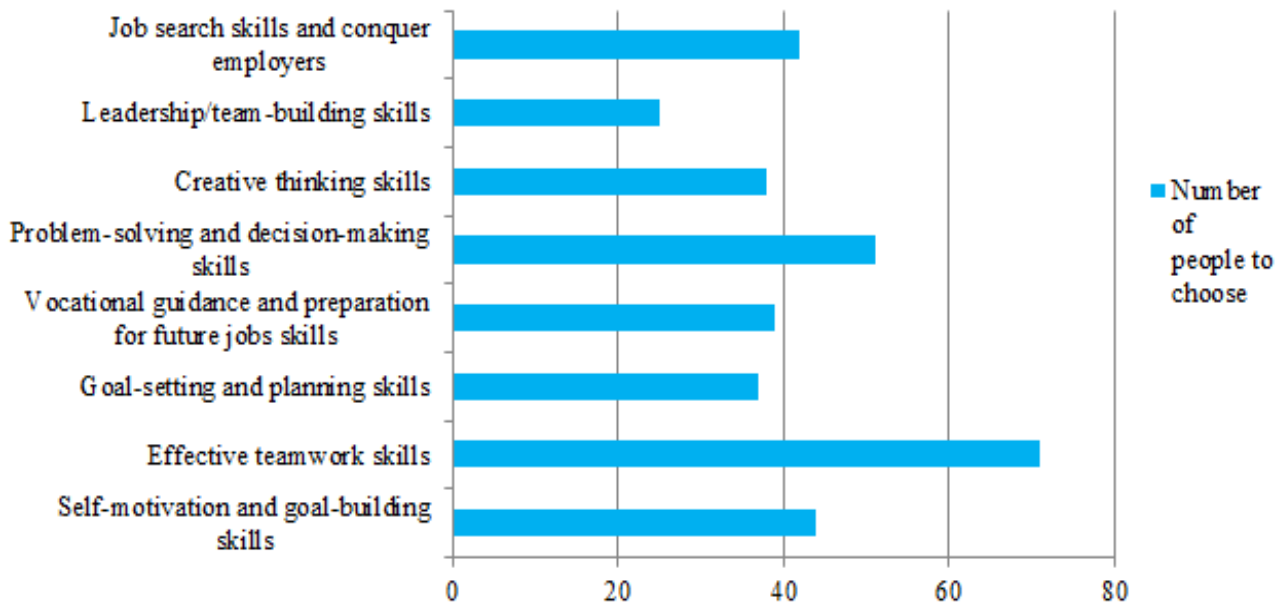

The time factor and class schedule can also partly affect the choice of subject and skill that students want. Besides the above question, I want to find out the perception of HUFI students on soft skills trained at the school. Another question was also added to the survey to ensure the accuracy of the student's perceived need for any skill. The question: 
"In the soft skills that Hufi has included in the teaching and learning curriculum, which skills do you think are needed for yourself?" gave the following chart results.

\section{In the soft skills that Hufi has included in the teaching and learning curriculum, which skills do you think are needed for yourself?}

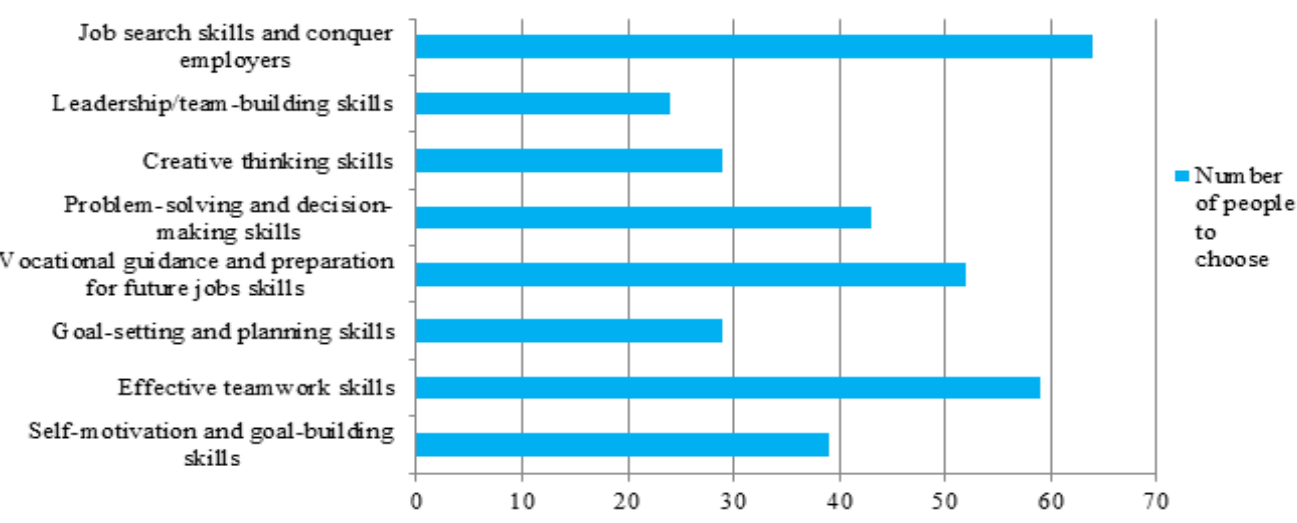

"Vocational guidance and prepare for future jobs skill" and "Job search skill and conquer employers" make up a high percentage of the eight skills outlined. Because the ultimate purpose of studying is also to have a stable job that suits you. The effect it brings can be easily seen through its name. With the aim of wanting students with career guidance skills to be able to see what type of work they are suitable for and the skills to best prepare for a job. After participating in the course, it will more or less help us to have good preparation skills when applying for a job from basic things such as the refinement of a CV, or how to handle questions when asked. interview. Both skills to conquer employers through words or gestures, each action in the interview will also be fully communicated to you when participating in this soft skills course.

"Effective teamwork skill" is the most chosen by students to study and is also a skill that students appreciate about its necessity. Today it is easy to do anything if have collaborated, but it also has a downside if people in a team are not only used to working independently. Those who do not equip themselves with the skill to adapt to the work that many people do, or can't stand the feeling of being dominated by not being able to always follow their own opinions will also counter the effectiveness of teamwork. Students who are used to working alone not only find it difficult to start collaborative jobs in the future, but it is also very difficult to succeed in most careers, not even in the process. The learning process requires collaboration. Teamwork skills appear to help students work effectively with the rest of the group and cultivate both leadership and team leadership skills when suggested. Therefore, it is very understandable that this skill is highly appreciated by HUFI students.

"Problem-solving and decision-making skills" belong to the top 4 skills that students HUFI consider essential. This is really a "golden" skill no matter what job you apply for, in any field or industry. Problem-solving skills help to deal with difficult and unexpected situations when encountered. Problem-solving skills involve active listening, analysis, research, creativity, and communication skills. The possessor of this skill has a quick reaction, good thinking, intelligence, and understanding. If you can improve your problem-solving skills, you will achieve great success at work.

The remaining soft skills are less selective but that does not mean they are not important such as "Creative thinking skills". No one can guarantee that everything that happens in everyone's life will be favorable. malfunction, misunderstanding, impact are a part of work and life. People who are used to following certain rules and routines while it is enough to deal with repetitive daily tasks will struggle if problems arise. Your ability to 

and future jobs?

use your knowledge to find answers to pressing problems and come up with possible solutions will demonstrate that you can handle and excel at your job. And that has been communicated to students when taking the training course "Creative thinking skills" and this course will help create people with creativity, the ability to understand the problems at hand and the solutions.

The condition of four skills makes HUFI students somewhat limited in all soft skills courses. Therefore, HUFI students have considered choosing the right skills for themselves, and of course, the remaining skills are equally necessary and HUFI students also attach great importance to the role of soft skills. This is demonstrated by the survey results with the question is: Do you feel soft skills are necessary for the learning process
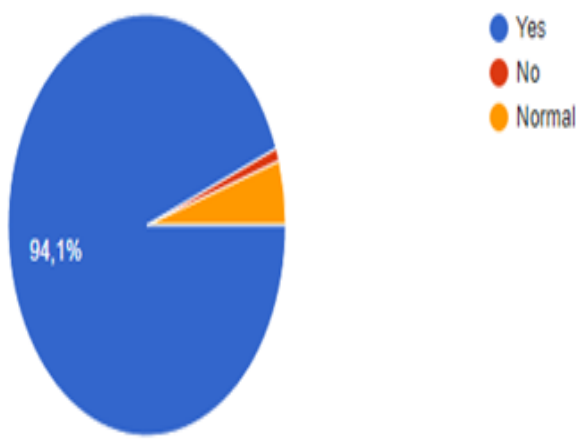

Do you feel soft skills are necessary for the learning process

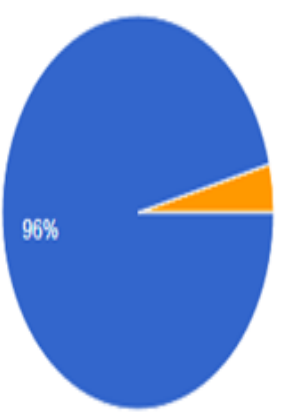

Do you feel soft skills are necessary for the future job?
One of the first successes of bringing soft skills to students is that students understand and see its role. What is even more encouraging is that HUFI students also like this subject.

263 264 265 266

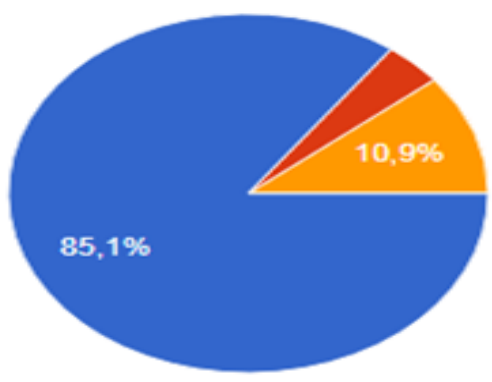

\section{Do you like learning soft skills?}

The answers received were all "yes" with nearly $90 \%$ for the question "Do you like learning soft skills?" showing that students love and care about soft skills, but it is surprising that some students have marked "no" in the answer of the question "If HUFI is not required to study soft skills, will you still apply?" though students themselves to like this subject. 


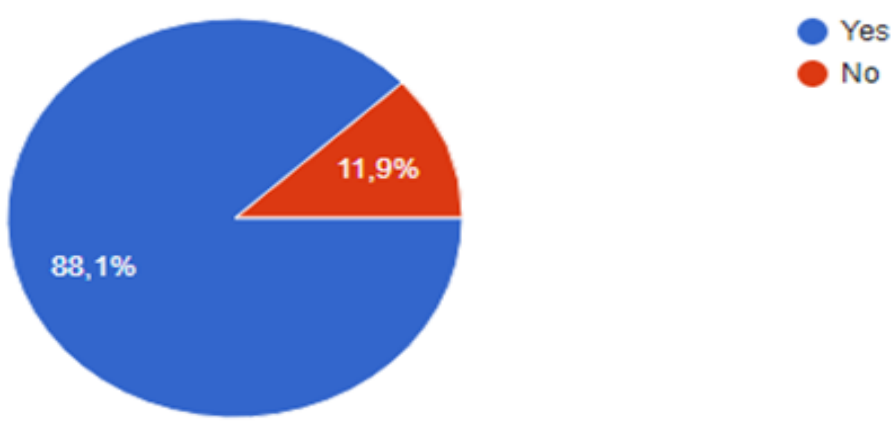

\section{If HUFI is not required to study soft skills, will you still apply?}

So what needs to be asked here is what factors make students not want to participate in soft skills training even though they love it and know the necessity of it.

First, the time factor is put in place, because these soft skills courses are scheduled around the weekend, or in the evening to ensure they do not coincide with the module lessons. This arrangement is suitable for students' learning, which partly affects the students' after-hours activities such as part-time work, activities, etc.

Second, the element of excitement is also put in place, because Soft skills courses are usually arranged with a large number of students and most lessons are communicated to students in the form of listening. Partly causing boredom when students do not practice much.

Third, the relevant factor, students are limited within the framework of eight skills, there are not many choices for students, so the desire to participate in the skills they want is also limited.

To find out more about the students' wishes, the survey has a question section "What soft skills would you like HUFI to add to the teaching and learning program?" and the answers received quite a lot. In addition to the desire to learn all the soft skills at school, there are also some skills that HUFI students propose to add to the program such as emotional control skills, presentation skills, time management skills, practical application skills. economics, oratory skills, and especially communication skills are most recommended.

Communication is simply the act of transferring information from one place, person, or group to another (Interpersonal Communication Skills). Communication skills are also taught at the school, but mainly for economics and foreign languages. This skill is not only appreciated by HUFI students but also interested in society when people always interact with each other by communicating. Whether it's face-to-face or written communication is important and we should hone this soft skill. Successful communication involves many factors. Verbal communication refers to the ability to speak clearly and accurately. Nonverbal communication includes the ability to show positive facial and body expressions. Written communication refers to your ingenuity in composing texts, messages, and other types of documents. Visual communication involves your ability to convey information using images and other visual means. Active listening is also considered an important communication skill because it helps you to listen and understand what others are saying. You need to be able to listen to know how to communicate well with people. Without strong listening skills, any attempt at communication will be one-sided and may not work.

Although there are still some limitations and factors that negatively affect soft skills training at HUFI, their effectiveness cannot be denied for HUFI students. They also see it after completing each soft skill training course. They all feel more confident, work in groups more effectively, find jobs easier, and especially have $0 \%$ for the choice of thinking that learning soft skills is not effective for them. 


\section{Conclusions}

It is not very easy to acquire soft skills so if you are an individual who is lacking on this front, then you should try to improve it. Any skill, whether formed quickly or slowly, stable or loose, depends on the subject's desire, determination, and receptive capacity; practice, the complexity of the skill itself. Many companies as well as schools, organize programs to training their employees so that they are able to develop their soft skills. Looking at the future, HUFI is a school that not only trains and imparts the hard knowledge of each sector. Looking at the future, HUFI has offered soft skills classes with support the policy of free teaching just with the desire that its students become almighty workforce and succeed in life and career. What is successful is that students do not disappoint the school's expectations when they understand and see the role of soft skills. Students actively absorb, practice and like soft skills courses. Soft skills have brought students clear effects that make HUFI students more favorable in all aspects of life. Soft skills courses full of comfort and no pressure gradually become the place where students acquire, practice, and soft skills in the most natural and comfortable way.

316

317

318

319

320

321

322

323

324

325

326

327

328

329

330

Conflicts of Interest: The authors declare no conflict of interest.

\section{Patents}

331

332

333

334

335

336

337

338

339

340

341

342

343

344

345

346

347

348

349

350

351

352

17. Tomaszewski, M. (2021, April 14). Hard Skills. Zety. 